\title{
Affective Experience, Desire, and Reasons for Action
}

\author{
Declan Smithies and Jeremy Weiss \\ Forthcoming in Analytic Philosophy
}

What is the role of affective experience in explaining how our desires provide us with reasons for action? When we desire that $p$, we are thereby disposed to feel attracted to the prospect that $p$, or to feel averse to the prospect that not- $p$. In this paper, we argue that affective experiences - including feelings of attraction and aversion - provide us with reasons for action in virtue of their phenomenal character. Moreover, we argue that desires provide us with reasons for action only insofar as they are dispositions to have affective experiences. On this account, affective experience has a central role to play in explaining how desires provide reasons for action.

We motivate this proposal by considering Warren Quinn's (1993) radioman. He is disposed to turn on radios, although he is not disposed to feel attracted to turning them on. Quinn claims (and we agree) that he has no reason to turn on radios. But orthodox versions of functionalism, according to which desire is a state that combines with belief to motivate action, imply that he does have a desire to turn on radios. These versions of functionalism cannot explain the normative role of desire in providing reasons for action.

Our main aim in this paper is to give an account of desire that explains how it can play its distinctive normative role in providing reasons for action. First, we argue in support of Quinn's intuition that radioman has no reasons to turn on radios. Second, we argue that radioman has no desire to turn on radios, since his motivational states give him no reason for turning them on. Third, we argue that our desires provide us with reasons for action only because they are dispositions to make us feel attracted to the things we desire.

Here is the plan for the paper. Section 1 outlines our account of affective experience. Section 2 introduces Quinn's radioman. Section 3 argues that radioman has no reason to turn on radios, since he violates a reflective access constraint on reasons. Section 4 explains why radioman has no reason to turn on radios: because he has no affective experience. Section 5 defends this explanation against alternatives. Section 6 argues that desires provide reasons for action only because they are dispositions to have affective experiences. Section 7 defends this theory against more orthodox versions of functionalism that explain desire in terms of its motivational role. Section 8 concludes. 


\section{Affective Experience}

What is an affective experience? As we use the term, an affective experience is an experience that presents its objects in a positively or negatively valenced way. To explain what we mean, we'll begin with some examples.

Our first example is the feeling of desire. When you feel the desire to spend time with someone, for example, you feel attracted to the prospect of spending time with them. When you feel the desire to avoid someone, on the other hand, you feel averse to the prospect of spending time with them. These are different feelings. They don't just differ in what they motivate you to do, or in what they give you reasons to do, but also in how they feel. Feeling attracted to something is a way of feeling positively oriented towards that thing, whereas feeling averse to it is a way of feeling negatively oriented towards it. This is a difference in what it's like for you to have the experience; that is, it's a difference in its phenomenal character.

Our second example concerns the distinction between pleasure and pain. When a sensation feels pleasurable, you like having it, whereas when it feels unpleasant, you dislike having it. A sensation can feel pleasurable for a while, but then become unpleasant when you've had too much of it, as for example when your shoulders are massaged for too long. These are two different ways of feeling about the same sensation. One is a way of feeling positively about the sensation, while the other is a way of feeling negatively towards the same sensation - or, perhaps better, towards the bodily condition that the sensation represents.

Our third example involves the experience of bodily appetites, such as hunger, thirst, or sexual arousal. When you feel hungry, you feel attracted towards eating, whereas when you feel satiated, you feel averse towards eating. These are two different ways of feeling about the same state of affairs. One is a way of feeling positively about this state of affairs, while the other is a way of feeling negatively about it.

Our final example involves basic emotional feelings, such as fear, anger, and disgust, although similar points extend to more complex feelings, such as guilt, shame, and pride. These, too, are positive and negative feelings. Consider the phenomenal difference between feeling afraid and feeling angry about a barking dog. These are two different ways of feeling negatively about the same state of affairs. Although they are different feelings, there is 
something in common between them insofar as they are both ways of feeling negatively about the same state of affairs.

What do these affective experiences have in common? They are all phenomenally conscious, intentional, and valenced. These three properties, and the relations between them, will play a crucial role in our account of the normative role of affective experience, so we'll begin by discussing them in some depth.

First, all affective experiences are phenomenally conscious in the sense that there's something it's like for us to have them. They all have some phenomenal character. Two experiences have the same phenomenal character if and only if what it's like to have the one is the same as what it's like to have the other. Now, there are many ways of typing affective experiences by their phenomenal character. Some are highly determinable, such as the generic feeling of pain, while others are more determinate, such as the specific feeling of pain associated with migraine. ${ }^{1}$ There is a kind of determinable phenomenal character shared by all positive feelings, and by all negative feelings, although there are also more determinate phenomenal respects in which they vary.

Second, all affective experiences are intentional in the sense that they are about or directed at things. The "intentional object" of an affective experience is whatever it is about, while the "intentional content" of an affective experience is the way in which its intentional object is represented to be. Some affective experiences are about parts of the body, including bodily sensations, such as pain and orgasm. Others are about external objects; for instance, your feeling of fear might be directed at the dog that is barking at you. It sometimes said that there are "objectless" moods and emotions, such as undirected anxiety and depression, which have no intentional content. Although these states are about nothing in particular, it doesn't follow that they're about nothing at all. Arguably, these negative feelings, or standing dispositions to have negative feelings, are directed towards things in general, rather than towards anything in particular. $^{2}$

\footnotetext{
${ }^{1}$ Sprigge 1988 makes this point in defending phenomenological theories of pleasure and pain against the so-called "heterogeneity objection".

${ }^{2}$ See Tye 1995: Ch. 4 and Crane 2009 for more detailed discussion of the intentionality of bodily sensations, emotions, and moods.
} 
Third, all affective experiences are valenced in the sense that they represent their intentional objects in a positive or negative way. It is a further question whether the valenced orientation of an affective experience is built into its intentional content or its intentional attitude-type. Is it a valenced attitude towards a neutral content or a neutral attitude towards a valenced content? On the content view, the valence of affective experience is built into its content: for instance, it represents its objects as having positive or negative value. On the attitude view, in contrast, the valence of affective experience is built into its attitude-type, rather than its content: for instance, it is a positive or negative way of representing its intentional content. In this paper, we'll remain neutral between the content view and the attitude view, although our sympathies align more closely with the attitude view. ${ }^{3}$

In summary, all affective experiences are phenomenal, intentional, and valenced. What is the relationship between the phenomenal character of an affective experience and its valenced orientation towards an intentional content? In our view, there is not merely an accidental relation between these properties. On the contrary, the phenomenal character of an affective experience is identical with a valenced orientation towards an intentional content.

This proposal can be located within the more general framework of intentionalism. ${ }^{4}$ Intentionalism is the thesis that the phenomenal character of experience is identical with a kind of intentional orientation towards an intentional content. On this view, all experience is intentional. Affective experience is set apart from other kinds of experience by its valenced intentionality. If we apply intentionalism to the specific case of affective experience, then we arrive at our proposal that the phenomenal character of an affective experience is identical with its valenced orientation towards an intentional content.

\footnotetext{
${ }^{3}$ See Weiss 2016 in defence of the attitude view. For the view that emotions represent value, see McDowell 1985, Goldie 2000, Johnston 2001, Döring 2007, Montague 2009, and Tappolet 2016. For the related claim that desire represents its objects under "the guise of the good”, see Anscombe 1963, Stampe 1987, Scanlon 1998, and Oddie 2005. For a contrasting view that desire is distinguished from belief by its distinctive force, rather than its content, see Chang 2004, Tenenbaum 2007, Schapiro 2009, and especially Schafer 2013.

${ }^{4}$ Intentionalism is also sometimes known as representationalism. The literature is huge, but some highlights include Tye 1995, Chalmers 2004, and Crane 2009.
} 
Intentionalism is neutral between the content view and the attitude view. Both views are compatible with intentionalism, since intentionality includes both intentional attitudes and intentional contents. Proponents of intentionalism disagree among themselves about the extent to which phenomenal differences can be explained in terms of differences in intentional content, rather than intentional attitude-types. ${ }^{5}$

According to intentionalism, the positive or negative valence of an affective experience supervenes upon its phenomenal character. After all, what it's like to feel positively about something is different from what it's like to feel negatively about the same thing. This is best explained by the thesis that the valenced orientation of an affective experience is an intrinsic feature of its phenomenal character. Let's call this phenomenal valence.

Similarly, affective experience has some intentional content that supervenes upon its phenomenal character. How things seem to your phenomenal duplicates is how things seem to you. Otherwise, your experience doesn't have the same phenomenal character as theirs. If their experiences are directed at different objects or properties, then there may be some overall difference in content. If so, then we can say that experience has two different kinds of intentional content: (i) phenomenal content, which supervenes on its phenomenal character; and (ii) externalist content, which supervenes also on its relations to the external world. ${ }^{6}$

On this account, the positive or negative valence of an affective experience is an intrinsic feature of its phenomenal character. The phenomenal valence of affective experience can be dissociated from its role in motivating action. Consider David Lewis's example of the madman, "who sometimes feels pain, just as we do, but . . is not in the least motivated to prevent pain or to get rid of it" $(1980,216)$. We can imagine swapping the motivational roles of pleasure and pain, so that the madman is motivated to prevent pleasure despite feeling attracted to it, and to pursue pain despite feeling averse to it. Since this is coherently conceivable, we cannot identify the phenomenal valence of affective experience with its role in motivating action. It is a sui generis kind of phenomenal character.

\footnotetext{
${ }^{5}$ Chalmers 2004 and Crane 2009 endorse impure as opposed to pure intentionalism: the thesis that the phenomenal character of experience is identical with its entire intentional nature, which includes not only its intentional content, but also its intentional attitude-type.

${ }^{6}$ See Horgan and Tienson 2002 and Chalmers 2004 for this two-level theory on which experience has both phenomenal contents and externalist contents.
} 
Nevertheless, the phenomenal valence of affective experience plays a role both in motivating action and providing reasons for action. Affective experience tends to motivate action because of its phenomenal character. If you feel positively about the prospect that $p$, then you're normally at least somewhat motivated to act in ways that you believe will make it true that $p$. Moreover, affective experience provides reasons for action because of its phenomenal character. If you feel positively about the prospect that $p$, then you thereby have at least some reason to make it true that $p$. When you're rational, the motivational role of affective experience matches its normative role. Sometimes, you act rationally on the basis of reasons provided by your affective experience.

Now, affective experience is not necessary for motivating action. Exactly the same motivational role could be played in an affective zombie - that is, a creature that has no affective experience at all. But it's a further question whether states that motivate action can provide reasons for action when they're not disposed to cause affective experience. We'll probe this question by considering Quinn's radioman, who is disposed to turn on radios, although he is not disposed to feel positively or negatively about turning them on. Radioman is a kind of partial affective zombie: he has states that play the same motivational role as our affective experiences, although they don't play the same phenomenal role. Can these motivational states provide him with reasons for action?

\section{Radioman}

Here is Quinn's description of radioman:

Suppose I am in a strange functional state that disposes me to turn on radios that I see to be turned off. Given the perception that a radio in my vicinity is turned off, I try, all other things being equal, to get it turned on. Does this state rationalize my choices? Told nothing more than this, one may certainly doubt that it does. But in the case I am imagining, this is all there is to the state. I do not turn on the radios on in order to hear music or get news. It is not that I have an inordinate appetite for entertainment or information. Indeed, I do not turn them on in order to hear anything. (1993, 236) 
Quinn raises two questions about this example: (i) does he have any reason to turn on radios? And (ii) does he have any desire to turn on radios? We'll argue in due course that there is an intimate connection between these two questions: if radioman has no reason to turn on radios, then it follows that he has no desire to turn on radios. However, we'll begin by setting aside questions about desire in order to focus on questions about reasons. To avoid begging any questions at the outset, we insist on describing the example without using the concept of desire. Our question is whether the radioman's disposition to turn on radios gives him a reason to turn on radios.

Here are some things we'll assume about radioman. First, his actions are intentional, not mere reflexes, since his behavior is mediated by his beliefs and other desires. For example, he'll enter a room when he believes there are radios inside, but not when he believes they're wired up with explosives. Second, he is disposed to turn on radios, but he is not disposed to feel positively about turning them on. After all, as Quinn says, the motivational disposition is "all there is to the state". Third, his disposition is "basic rather than instrumental". He has no instrumental reason to turn on radios, so if he has any reason at all, then it must be a noninstrumental reason. Our question is whether the mere disposition to turn on radios gives him any non-instrumental reason for turning them on.

Before going any further, we need to explain what it means to ask whether radioman has any reason to turn on radios. We'll make three points of clarification. First, we're asking a normative question about what radioman should do, rather than a psychological question about what he does and why he does it. In other words, we're interested in whether radioman has a normative reason to turn on radios, rather than a motivating or explanatory reason. Normative reasons are facts that explain what we should do, whereas motivating or explanatory reasons are facts that explain what we do and why we do it. ${ }^{7}$

Second, we're concerned with normative facts about what it's rational for radioman to do, rather than what it's advisable for him to do. We're asking how it makes sense for him to act in light of the limited information in his possession, rather than the full information that is available from an omniscient third-person perspective. In the standard terminology, we're asking what he subjectively ought to do, rather than what he objectively ought to do. There is a

\footnotetext{
${ }^{7}$ For background discussion of the distinction between normative and motivating reasons, see Parfit 1984: 118, Smith 1994: 94-8, Dancy 2000: 1-10, and Schroeder 2007: 10-15.
} 
distinction between subjective and objective senses of 'reason' that mirrors this distinction between subjective and objective senses of 'ought'. In the subjective sense, reasons are facts that contribute towards explaining normative facts about what it's rational for us to do, rather than what it's advisable for us to do. In this paper, we are exclusively concerned with reasons in the subjective sense, rather than the objective sense. ${ }^{8}$

Third, we're asking whether there are facts about the radioman that count to some degree in favor of the rationality of turning on radios. We're not asking whether they make it rational to turn on radios, all things considered. In other words, we're asking whether radioman has a defeasible reason to turn on radios, which may be defeated - that is, outweighed or undercut - by stronger reasons against doing so; say, because there are more productive or enjoyable ways to spend one's time. Such reasons are variously described in the literature as pro tanto or prima facie reasons.

In summary, our question is whether radioman has any defeasible, subjective, normative reason to turn on radios. Quinn says no. He writes:

I cannot see how this bizarre functional state in itself gives me even a prima facie reason to turn on radios, even those I can see to be available for cost-free onturning. It may help explain, causally, why I turn on a particular radio, but it does not make the act sensible. $(1993,237)$

We agree with Quinn's verdict about the case, but we don't wish to rest too much weight on the brute deliverance of intuition. Quinn himself gives no argument in defence of his verdict, but we aim to do better. In the next section, we'll argue for Quinn's verdict about the case by appealing to a reflective access constraint on reasons that can be motivated on independent grounds.

\footnotetext{
${ }^{8}$ On the distinction between rationality and advisability, see Gibbard 1990: 18-19. On the distinction between objective and subjective senses of 'reason', see Schroeder 2008.

${ }^{9}$ See Reisner 2013 on the related distinction between prima facie and pro tanto oughts.
} 


\section{The Reflective Access Constraint}

How can we motivate the claim that radioman has no reason to turn on radios? We'll begin by considering what radioman might reasonably conclude in reflecting on the rationality of his actions:

Why am I doing this? I don't feel like listening to the radio. And I don't enjoy turning on radios just for the hell of it. But then why am I wasting my time like this? It's not as if it benefits me in some other way, or anyone else for that matter. And the mere fact that I keep doing this doesn't mean that there's anything to be said for it. Come to think of it, there's nothing to be said for it at all. So, I don't really have any reason to turn on radios.

This seems like the only reasonable conclusion for radioman to draw. It's not rational for him to believe upon reflection that he has any reason to turn on radios. After all, there is nothing available to him upon reflection that plausibly counts in favor of turning on radios.

What about the dispositional state that motivates him to turn on radios? This state is disqualified for two reasons. First, it's not rational for radioman to believe on the basis of reflection alone that he is disposed to turn on radios. Rather, he needs to infer that he has this disposition by observing its effects on his behavior. Second, it's not rational for him to believe that this disposition gives him any reason to turn on radios. After all, the mere fact that someone is disposed to act in some way doesn't count at all in favor of the rationality of acting in that way. We'll revisit these points in due course.

We've just argued that it's rational for radioman to believe upon reflection that he has no reason to turn on radios. But does it follow that he has no reason to turn on radios? Perhaps radioman has some reason to turn on radios, although it's not rational for him to believe upon reflection that he does. However, this is ruled out by the reflective access constraint on reasons below:

The reflective access constraint: one has a reason to $\varphi$ only if it is epistemically rational for one to believe on the basis of reflection that one has a reason to $\varphi$. 
In this section, we'll aim to say just enough to motivate the reflective access constraint, and defend it against objections, although we've done this in much more detail elsewhere. ${ }^{10}$

Let's begin by clarifying the scope of the reflective access constraint. It applies to reasons for action as well as reasons for belief: as such, it unifies the practical and epistemic domains. It is a constraint on normative reasons, rather than motivating reasons: that is, our reasons for believing and acting, rather than the reasons for which we believe and act. But it applies only to normative reasons in the subjective sense, rather than the objective sense: these are facts that explain what it's rational for you to do, rather than what it's advisable for you to do. You can have objective reasons to $\varphi$ when it's not rational for you to believe this upon reflection, but you cannot have subjective reasons to $\varphi$ unless it's rational for you to believe this upon reflection. Indeed, the reflective access constraint provides a principled way of drawing the distinction between subjective and objective reasons in the first place.

It is often said that the reflective access constraint imposes an overly demanding intellectual requirement on having reasons for belief and action: namely, that you cannot have reasons for belief and action unless you're capable of articulating those reasons upon reflection. However, the reflective access constraint doesn't imply this. It implies that if you have a reason to $\varphi$, then it's epistemically rational for you to believe that you have a reason to $\varphi$. But there are many cases in which your evidence makes it rational for you believe a proposition, although you're incapable of believing it rationally on the basis of the evidence. Consider Sherlock Holmes and Dr. Watson: they have exactly the same evidence that Moriarty committed the murder, but only Holmes is capable of believing this rationally on the basis of the evidence.

Another common objection is that the reflective access constraint generates an infinite regress. Indeed, it does; but the regress is benign, rather than vicious. The reflective access constraint generates an infinite regress of reasons, but not an infinite regress of beliefs about reasons. If you have a reason to $\varphi$, then you have a reason to believe that you have a reason to $\varphi$, and so on ad infinitum. Compare: if you have a reason to believe that $p$, then you have a reason to believe that $p$ or $q$, and so on ad infinitum. The regress is benign, since

\footnotetext{
${ }^{10}$ Smithies (2012, forthcoming) argues for a reflective access constraint on epistemic reasons or epistemic justification and defends it against objections. Here, we extend the reflective access requirement from epistemic reasons to practical reasons.
} 
you're not rationally required to believe everything that you have reason to believe, so long as you don't disbelieve or withhold belief in those propositions instead.

Why should we accept the reflective access constraint on reasons? For one thing, it explains intuitions about cases. We don't just mean intuitions about radioman, since that would beg the question in this dialectical context. Similar reasoning extends to a much wider range of cases. Consider Ned Block's (1995) super-blindsighter, who is reliably disposed to form beliefs about objects in his blind field on the basis of unconscious vision. Intuitively, he has no reason to form these beliefs unless he has background evidence of his own reliability. After all, it is not epistemically rational for him to believe upon reflection that he has any reason to believe, say, that there is an $\mathrm{X}$ in his blind field. Given the reflective access constraint, it follows that he has no reason to believe there is an $\mathrm{X}$ in his blind field. His unconscious vision cannot give him reasons for belief because it cannot make it rational for him to believe upon reflection that he has any such reasons for belief. ${ }^{11}$

The reflective access constraint also explains the irrationality of akrasia in belief and action. Intuitively, it's irrational to $\varphi$ while disbelieving or withholding belief that it's rational for you to $\varphi$. According to the reflective access constraint, this is because you cannot have good reasons to $\varphi$ unless it's also rational for you to believe that you have those reasons. If the reflective access constraint is false, then you can have good reasons to $\varphi$ when it's not rational for you to believe that you have those reasons. In that case, it can be rationally permissible to $\varphi$ when it's also rationally permissible to disbelieve or to withhold belief that you have any good reason to $\varphi$. Plausibly, however, it is always irrational - or, anyway, less than perfectly rational - to be in this kind of akratic predicament.

This argument also supplies the response to an objection: namely, that the reflective access constraint is falsified by cases in which it's rational to believe false theories of rationality. The response is that it cannot be rational to believe false theories of rationality, since this would allow for the rationality of akrasia. ${ }^{12}$ This doesn't mean that anyone who believes a false theory of rationality is irrational, but only that they're less than perfectly

\footnotetext{
${ }^{11}$ See Smithies (2014, forthcoming) for further discussion of super-blindsight.

${ }^{12}$ See Smithies (forthcoming) for further discussion. Titelbaum argues on similar grounds for his fixed-point thesis: "Mistakes about . . . rationality are mistakes of rationality" (2015: 253).
} 
rational. No offense should be taken, of course, since that's true of all of us. None of us are perfectly rational, but some of us are more egregiously irrational than others.

Finally, the reflective access constraint captures a plausible connection between rationality and reflection. A rational belief or intention is one that has the potential to withstand fully rational reflection. The reflective access constraint guarantees this connection by ensuring that you have good reasons to $\varphi$ only if it is rational for you to believe on reflection that you have those reasons. If the reflective access constraint is false, then you can have good reasons to $\varphi$ even when it's not rational to believe on reflection that you have those reasons. In that case, a rational belief or intention that is based on good reasons would lack the potential to withstand fully rational reflection. Hence, the plausible connection between rationality and reflection is severed.

In this section, we've argued that radioman has no reason to turn on radios because he violates the reflective access constraint, which can be motivated on independent grounds. This does not yet fully explain why he has no reason to turn them on. The reflective access constraint is just a constraint on our possession of reasons. It doesn't explain how we come to possess reasons in the first place. Our aim in the next section is to explain why the states that motivate radioman to turn on radios cannot give him any reason for turning them on.

\section{What is Radioman Missing?}

We propose that radioman has no reason to turn on radios because the states that motivate him to turn on radios don't make him feel positively about turning them on. What's missing is any affective experience, or any disposition to have affective experience, that is positively valenced towards the prospect of turning on radios or negatively valenced towards the prospect of leaving them turned off. In particular, radioman feels no desire to turn on radios, notwithstanding the fact he is motivated to turn them on.

It's extremely plausible that some affective experiences are capable of providing us with reasons for action. If you feel attracted to turning on radios, just for its own sake, then you thereby have some reason for turning them on. We don't claim that all affective experiences provide reasons for action. There's a phenomenal difference between feeling attracted to something for its own sake and feeling attracted to it only as a means to some end. Moreover, this makes a normative difference too. If you feel attracted to turning on radios, but only because you feel averse towards silence, then the feeling of attraction 
towards turning on radios doesn't give you any extra reason for turning them on. Rather, it merely transmits the reason provided by your aversion to silence, given your reason to believe that turning on radios will make sound. We claim that only basic affective experiences - namely, those had for no further reason - provide reasons for action. These affective experiences provide reasons for action without standing in need of rational support by further reasons.

Our question is why the motivational states of the radioman cannot play the same kind of normative role. How are they relevantly different from affective experience? Our answer is that affective experience has phenomenal valence and phenomenal content. On the intentionalist theory we propose, the phenomenal character of affective experience is a way of representing an intentional content in a positively or negatively valenced way. Moreover, affective experience provides reasons for action in virtue of representing its intentional content in a positively or negatively valenced way. Therefore, we conclude, affective experience provides reasons for action in virtue of its phenomenal character.

To illustrate the point, suppose I feel attracted to the prospect of turning on radios. Why does my experience give me a reason to turn on radios, rather than doing something else, or nothing at all? There is a non-arbitrary connection between its phenomenal character and what it gives me a reason to do. One part of the story is that it's an intrinsic feature of its phenomenal character that it represents the content that I turn on radios. But this is not the whole story. After all, my perceptual experience might represent that I'm turning on radios without thereby giving me any reason to do this; after all, it doesn't represent its content in a positively valenced way. In contrast, my affective experience gives me a reason to turn on radios because it's an intrinsic feature of its phenomenal character that it represents this content in a positively valenced way. It is precisely because I feel positively about turning on radios, rather than negatively, or neutrally, that I have a reason for making its content true, rather than making it false, or doing nothing at all.

Why is it crucial that affective experience has its valenced intentionality built into its phenomenal character? This is crucial for explaining how affective experience provides reasons for action in a way that respects the reflective access constraint. Affective experience does a kind of double duty: it provides not only reasons for action, but also introspective reasons for belief about affective experience. More specifically, affective experience provides 
introspective reasons for belief about the phenomenal features in virtue of which it provides reasons for action - namely, its phenomenal valence and its phenomenal content.

To illustrate the point, let's revisit our example. If I feel attracted to the prospect of turning on radios, then it is epistemically rational for me to believe:

(1) I feel attracted to the prospect of turning on radios [by introspection]

(2) If I feel attracted to the prospect of turning on radios, then I have a reason to turn on radios [by a priori reflection]

(3) Therefore, I have a reason to turn on radios [by deduction from (1) and (2)]

The key point is that my affective experience has introspectible features that seem upon reflection to count in favor of turning on radios. In this way, my affective experience provides me with a reason for action that satisfies the reflective access constraint. In contrast, the motivational states of the radioman don't have introspectible features that seem upon reflection to count in favor of turning on radios. This is why they cannot provide reasons for action in a way that satisfies the reflective access requirement.

We can apply similar reasoning to explain the epistemological difference between perceptual experience and unconscious perception in super-blindsight. Affective experience provides reasons for action, whereas perceptual experience provides reasons for belief, but both provide reasons in virtue of their phenomenal character. On our intentionalist theory, the phenomenal character of perceptual experience is a way of representing its content with assertive force, rather than valenced force: that is, roughly, it represents its content as true, rather than representing it in a positive light. And because it has the phenomenal character of representing its content with assertive force, it thereby provides reason for believing that its content is true.

This is crucial for explaining how perceptual experience provides reasons for belief that satisfy the reflective access constraint. When I have a visual experience in which it seems that I have hands, it's epistemically rational for me to believe:

(1) I'm having a visual experience in which it seems that I have hands [by introspection]

(2) If I'm having a visual experience in which it seems that I have hands, then I have a reason to believe that I have hands [by a priori reflection] 
(3) Therefore, I have a reason to believe that I have hands [by deduction]

The key point is that my perceptual experience has introspectible features that seem upon reflection to count in favor of believing that I have hands. In this way, my perceptual experience provides me with a reason for belief that satisfies the reflective access constraint. In contrast, unconscious perception in super-blindsight doesn't satisfy this condition because it lacks the requisite phenomenal force and phenomenal content.

Not all of my reasons for action have their source in affective experiences I'm having right now. I can also have reasons for acting because I'm disposed to have certain affective experiences, even when the disposition is not currently being manifested. Suppose I have a standing aversion to the taste of tomatoes, which is disposed to cause occurrent feelings of aversion whenever I think about eating them. If so, then I have a standing reason to avoid eating tomatoes. Moreover, I can rationally act upon this reason when filling my plate from the salad bar even if I'm engrossed in conversation and so giving no thought to what it's like to eat tomatoes. It's enough that I have a standing disposition to feel revulsion when I consciously think about eating tomatoes.

Just as affective experiences can provide reasons for action in virtue of their phenomenal character, so affective dispositions can provide reasons for action in virtue of being disposed to cause the phenomenal character of affective experience. Affective dispositions, like affective experiences, are valenced orientations towards an intentional content. In fact, they inherit their valenced orientation towards an intentional content from the affective experiences they are disposed to cause. They are individuated by their dispositions to cause affective experiences: these dispositions are what make them the valenced and intentional states they are.

Affective dispositions, like affective experiences, provide reasons for action in a way that satisfies the reflective access constraint. After all, I can know by reflection how I'm disposed to feel about tasting tomatoes. For instance, I can just manifest the disposition by thinking about tasting tomatoes and considering how I feel about it. Even when I'm not currently manifesting the disposition, I can have standing knowledge of how I'm disposed to 
feel, so long as the affective disposition plays the right kind of role in causally sustaining or partially constituting my standing belief that I have this disposition. ${ }^{13}$

We conclude that radioman has no reason to turn on radios because the states that motivate him to turn on radios don't make him feel positively about turning them on. What he is missing is any affective experience, or any disposition to have affective experience, that is positively valenced towards the prospect of turning on radios or negatively valenced towards the prospect of leaving them turned off.

\section{Alternative Explanations}

We've argued that radioman has no reason to turn on radios because he is not disposed to feel positively about turning them on. The missing ingredient is affective experience. In this section, we'll argue against rival explanations, according to which radioman has no reason to turn on radios unless (i) there is some value in turning on radios, or (ii) he believes there is some value in turning on radios, or (iii) he enjoys turning on radios. The objection is that affective experience cannot provide reasons for action unless these conditions are satisfied. We'll argue in response that affective experience can provide reasons for action even when none of these conditions are satisfied.

\subsection{Value-Based Reasons}

The first proposal we'll consider is that radioman has no reason to turn on radios because there is no value in doing so. According to this proposal, reasons for action are provided by the value of the states of affairs they bring about. ${ }^{14}$

Proponents of value-based theories of reasons sometimes argue that if there is no value in $\varphi$-ing, then the mere fact that one desires to $\varphi$, or feels attracted towards $\varphi$-ing, cannot give one any reason to $\varphi$. Consider Donald Davidson's $(1963,686)$ example of the

\footnotetext{
${ }^{13}$ See Shoemaker (1996) for the proposal that rational agents have reflective knowledge of their beliefs and desires when their standing second-order beliefs are partially constituted by the dispositions that realize their first-order beliefs and desires.

${ }^{14}$ See Parfit 1984: Ch. 6, Scanlon 1998: Ch. 1, Raz 1999: Ch. 3, and Dancy 2000: Ch. 2. On buckpassing accounts of value, reasons for action are provided not by facts about value, but rather by the non-evaluative facts on which they supervene.
} 
man who feels a yen to drink a can of paint. It's very natural to say that he has no reason to act on it. After all, drinking the paint would certainly make him very sick. As Jonathan Dancy writes, "A desire to $\varphi$ cannot itself give us any reason to $\varphi$. For if $\varphi$-ing is silly or even just not very sensible, wanting to $\varphi$ does not make it less silly or a bit more sensible" $(2000,32)$.

In reply, we maintain that feeling a yen to drink a can of paint does give you a reason to drink it. If you know that drinking the paint will make you sick, then your reason to drink the paint is outweighed by a much stronger reason not to do so. Strictly speaking, it's false that you have no reason to drink the paint, although saying this communicates the truth that you have no reason strong enough to rationally act upon. ${ }^{15}$ In principle, though, we can imagine cases in which you have no reason to believe that you will get sick or no reason to care. In such cases, feeling a yen to drink a can of paint might give you a reason strong enough to rationally act upon.

As we're using the terms, your reasons determine which actions are rational given the limited information in your possession, rather than which actions are advisable given the full information that is available from a third-person perspective. In Bernard Williams' (1981) well-known example, it is rational to drink the cocktail because you want gin and you have reason to believe it contains gin, but it is inadvisable to drink it because it contains petrol. In that case, you have good reasons to drink the cocktail insofar as you have good reasons to believe it contains gin, and no good reason to believe it contains petrol. ${ }^{16}$

In general, it's not necessary for having a reason to $\varphi$ that there is any value in $\varphi$-ing. It's sufficient that you have a reason to believe that there is some value in $\varphi$-ing even if there is none. But affective experience meets this condition. If you feel positively about $\varphi$-ing, then you thereby have a reason to believe that there is some value in $\varphi$-ing, since your affective

${ }^{15}$ See Schroeder 2007: 92-7 for additional argument that we shouldn't put too much theoretical weight on negative existential claims about reasons.

${ }^{16}$ We're not denying that there is any objective sense of 'reason' on which an action can be rational when one has no reason to perform it, but we insist that there is also a subjective sense of 'reason' on which reasons count in favor of action by making them rational. 
experience presents the prospect of $\varphi$-ing in a positive light. So, feeling positively about $\varphi$ ing is sufficient to give you a reason to $\varphi$ even when there is no value in $\varphi$-ing. ${ }^{17}$

In conclusion, you can have reasons to act in ways that have no value, so long as you have reasons to believe there is value in so acting. What it's rational for you to believe and do is determined by facts about your mental states, rather than non-mental facts about value. It's a further question which mental states play a role in determining the rationality of belief and action. We'll now argue that the rationality of action depends not just on beliefs about value, but also crucially on affective experiences.

\subsection{Evaluative Belief}

The second proposal we'll consider is that radioman has no reason to turn on radios because he doesn't believe there is any value in turning on radios. This is the moral that Quinn draws from his discussion of radioman:

A noncognitive pro-attitude, conceived as a psychological state whose salient function is to dispose an agent to act, is just not the kind of thing that can rationalize. That I am psychologically set up to head in a certain way, cannot by itself rationalize my Will's going along with the setup. For that I need the thought that the direction in which I am psychologically pointed leads to something good (either in act or result) or takes me away from something bad. $(1993,242)$

Here is one way to motivate Quinn's proposal. Unless radioman thinks there is some value in turning on radios, there is nothing to distinguish a feeling of attraction towards turning on radios from a mere urge or feeling of compulsion to do so. A mere feeling of compulsion, however, cannot provide any reason for action. Therefore, radioman has no reason to turn on radios unless he thinks there is some value in doing so. As T. M. Scanlon argues, radioman "feels an urge to turn on every radio he sees" but "it is not that he sees anything good about radios' being turned on" and so "the urge to turn on radios is bizarre because it completely lacks this evaluative element" $(1998,38)$.

\footnotetext{
${ }^{17}$ For discussion of the role that affective experiences of emotion or desire play in justifying beliefs about value, see Johnston 2001, Oddie 2005, Döring 2007, and Schafer 2013.
} 
We reply that feelings of attraction are set apart from feelings of compulsion because they present their contents in a positive light. A feeling of compulsion represents its content as inevitable, but it doesn't thereby represent its content in a positive light. You might feel an irresistible urge to vomit, for example, without thereby representing that outcome in a positive light or its absence in a negative light. An experience that has no phenomenal valence cannot provide reasons for action in virtue of its phenomenal character. ${ }^{18}$

If affective experience is distinct from evaluative belief, then in what sense is it positively or negatively valenced? As we explained in section 1, the content view and the attitude view give different answers to this question. On the content view, affective experience is a neutral representation of a valenced content, whereas on the attitude view, it is a valenced representation of a neutral content. On both views, however, affective experience is distinct from evaluative belief. In cases of recalcitrant desire, for example, you can feel attracted to something that you know (and hence believe) has no value at all.

Moreover, affective experience can provide reasons for action in the absence of any corresponding evaluative belief. Here are two arguments for this claim. First, human infants and non-human animals can have affective experiences that provide reasons for action without grasping the evaluative concepts needed to form beliefs about value. For instance, an animal that feels hungry has a reason to seek food even if it cannot form beliefs about the value of doing so. Second, even human adults can have reasons for action provided by affective experiences that conflict with their evaluative beliefs. For example, in Nomy Arpaly's (2003) version of Mark Twain's story, Huck Finn's feeling of sympathy for Jim gives him a good reason to help him escape slavery, despite his belief that morality requires turning him over to the authorities.

As we've just seen, evaluative belief is not necessary for having reasons for action, but it's also not sufficient. Suppose radioman forms a completely irrational belief that there is some value in turning on radios. This cannot give radioman any reason to turn on radios. After all, beliefs cannot provide reasons for belief or action unless they are rationally based

${ }^{18}$ Compare Schroeder's (2007, Ch. 8) proposal that desires are dispositions to be motivated by considerations that strike us as salient. We find this unsatisfying because radioman may be moved to action by the attention-grabbing thought that there are radios upstairs without thereby feeling positively about going upstairs and turning on radios. 
on reasons themselves. ${ }^{19}$ What's necessary for having reasons for action is that you have some reason to believe there is value in acting whether or not you actually believe this. Again, affective experience meets this condition. If you feel positively about $\varphi$-ing, then you thereby have a reason to believe that there is some value in $\varphi$-ing. Thus, feeling positively about $\varphi$ ing gives you a reason to $\varphi$ even when you don't believe there is any value in $\varphi$-ing.

\subsection{Pleasure}

The final proposal we'll consider is that radioman has no reason to turn on radios because he doesn't enjoy turning on radios; that is, he feels no pleasure in doing so. As Michael Smith notes, "People who are disposed to make things a certain way also generally like it when things are that way" $(2011,82)$. But radioman illustrates a conceptual distinction between pleasure and motivation: he is motivated to turn on radios, but he feels no pleasure in doing so. Thus, Smith concludes, "What's missing is his being such that he would like the world to be the way he is disposed to make it" $(2011,93)$.

As Smith recognizes, pleasure involves an affective component. This is why he describes radioman as lacking an "affective orientation towards the outcome of his turning on radios" $(2011,93)$. When he says that we have an "affective orientation" towards certain ways the world might be, what he means is that "we would experience a positive affect, were things thus - in short, we would like it" $(2012,82)$.

Nevertheless, Smith's proposal should not be confused with ours. After all, it's one thing to feel attracted to the prospect that $p$, but it's another thing to feel pleasure in the apparent presence of the fact that $p$. Both are affective experiences, but they are distinct species of the genus. You can feel attracted to things that you don't enjoy, and vice versa. For example, you might feel attracted to retirement when in fact the reality will bore you, and you might find yourself enjoying a cocktail party that you dreaded beforehand. What is more, feelings of attraction themselves are not always pleasurable; for example, bodily cravings and feelings of unrequited love can be intensely painful.

\footnotetext{
${ }^{19}$ Broome 1999 argues that if I form an irrational belief that I have a reason to $\varphi$, then I'm subject to a rational requirement either to $\varphi$ or to give up my belief, but it doesn't follow that I have any reason to $\varphi$.
} 
We claim that our reasons for action have their source in our dispositions to feel attraction towards things, rather than our dispositions to take pleasure in them. After all, we endorse a reflective access constraint on reasons. You're in a position to know by reflection whether you're now disposed to feel attracted to the prospect of $\varphi$-ing, but not whether you're disposed to enjoy $\varphi$-ing, since you might feel attracted to things that you wouldn't actually enjoy. So, hedonic dispositions cannot provide reasons for action in a way that satisfies the reflective access constraint.

It's not necessary for having a reason to $\varphi$ that you're disposed to enjoy $\varphi$-ing. After all, it's sufficient that you have a reason to believe that you would enjoy $\varphi$-ing even if in fact that's false. Of course, this isn't necessary, since an affective experience can give you a reason to $\varphi$ without thereby giving you any reason to believe that you would enjoy $\varphi$-ing. Consider a firefighter who feels obligated to rescue a child from a burning building despite knowing the risk of incurring fatal injuries. What's necessary for having a reason for action is that you have a reason to believe that there is some value in $\varphi$-ing. Once again, affective experience satisfies this condition. If you feel positively about $\varphi$-ing, then you thereby have a reason to believe that there is some value in $\varphi$-ing. So, feeling positively about $\varphi$-ing is sufficient to give you a reason to $\varphi$ even when you're not disposed to enjoy $\varphi$-ing and you have no reason to believe that you're disposed to enjoy $\varphi$-ing.

In conclusion, affective experience is sufficient to provide reasons for acting even when you're not disposed to enjoy acting, there is no other value in acting, and you don't believe there is any pleasure or other value in so acting.

\section{The Affective Theory of Desire}

Recall that Quinn raises two questions about radioman: (i) does he have any reason to turn on radios? And (ii) does he have any desire to turn on radios? We'll now argue that these two questions are intimately related: if radioman has no reason to turn on radios, as we've argued, then it follows that he has no desire to turn on radios.

Quinn stipulates that radioman has no instrumental desire to turn on radios: after all, his disposition is "basic rather than instrumental" $(1993,236)$. So, if he has any desire to turn on radios, then it must be a basic desire: that is, he doesn't have this desire in virtue of having any other beliefs or desires. Our question is whether the dispositional state that motivates 
him to turn on radios is a basic desire to turn on radios. Quinn raises this question only to set it aside. He writes:

I have been careful not to raise the question whether my odd functional state is in fact a basic desire to turn on radios. I have not raised it because I am not at all sure of the answer. What I feel sure of, and what I have argued, is that whether or not the mere functional state is sufficient, it cannot ground reasons for action. (1993, 246-7)

Quinn's agnosticism leaves us with two options. On the first option, radioman has a basic desire to turn on radios, but he has no reason to turn on radios, so it follows that not all basic desires provide reasons for action. On the second option, all basic desires provide reasons for action, but radioman has no reason to turn on radios, so it follows that he has no basic desire to turn on radios.

We reject the first option and endorse the second option instead. As we'll explain, this is because desire plays a normative role in providing reasons for action, and not just a causal role in motivating action. Consider David Lewis's (1970) analytical functionalism, according to which theoretical terms are functionally analyzed in terms of their associated theoretical roles. Lewis extends this proposal from scientific theories to folk theories, but this should not obscure the fact that our folk theory of mind is distinctive insofar as it contains normative elements. According to our folk theory of mind, beliefs and desires do not just play a causal role in motivating action, since they also play a normative role in providing reasons for action. Analytical functionalism provides no basis for privileging causal roles over normative roles in the analysis of belief and desire. We therefore conclude that nothing deserves the name 'desire' unless it plays the right kind of normative role.

This raises two further questions. First, what is the distinctive normative role of basic desire? And second, what must our basic desires be like in order to play their distinctive normative role? Our answers to these questions will supply us with the premises we need to argue for what we call the affective theory of basic desire, according to which all basic desires are affective experiences, or dispositions to have affective experiences.

Let's begin with our first question. What is the distinctive normative role of basic desire? Our answer is that all basic desires provide reasons for action without standing in need of any further rational support by reasons. We're not endorsing the neo-Humean 
theory that all reasons for action are provided by desires. ${ }^{20} \mathrm{We}$ can allow that some reasons for action are provided by reasons for evaluative beliefs, which are not themselves based on reasons provided by desires. We're also not claiming that all desires provide reasons for action. Arguably, desires cannot provide reasons for action when they're based on irrational beliefs, since that generates implausible bootstrapping. Similarly, desires cannot provide reasons for action when they are based on rational beliefs, since that generates implausible double counting. For instance, desiring to avoid someone because of paranoid beliefs about them doesn't give you any reason to avoid them. Moreover, desiring to avoid someone because of perfectly rational beliefs about them doesn't give you any extra reason to avoid them in addition to the reasons that make your belief rational in the first place.

Our normative claim is restricted to basic desires - that is, desires that are not based on reasons of any kind, whether those reasons are provided by beliefs or other desires. ${ }^{21}$ Some things we desire because they are instrumental to other things we desire. Other things we desire because we believe they have value that is independent of other things we desire. Thus, many of our desires are based on reasons provided by other beliefs or desires. But some things we desire for no further reason: perhaps these things seem good to us, but if so, that is a consequence of the fact that we desire them, and not a reason for which we desire them. ${ }^{22}$ These are our basic desires.

Our account of the normative role of basic desires is motivated by a certain kind of modest foundationalism about the structure of epistemic and practical reasons. Perception is often thought to play a foundational epistemic role in providing epistemic reasons for belief without standing in need of any further rational support by reasons. In a slogan, perceptions are "unmoved ... movers of the epistemic domain" (BonJour 1985, 17). We envisage the same kind of foundational role for basic desires: they are "unmoved movers" of the practical domain. On this view, basic desires provide practical reasons for intention and action

\footnotetext{
${ }^{20}$ Proponents of the Humean theory include Williams 1981, Hubin 1991, and Schroeder 2007, while opponents include Nagel 1970, Korsgaard 1986, and Smith 1994.

${ }^{21}$ Our basic desires are what Nagel $(1970,29-30)$ calls unmotivated desires; they are desires that are not held on the basis of any motivating reasons at all.

${ }^{22}$ Chang $(2004,68)$ makes this point in the course of criticizing Scanlon's (1998) account of desires as dispositions to think or judge that we have reasons to pursue their objects.
} 
without standing in need of any further rational support by reasons. As Karl Schafer puts the point, "Just as desires play the role of standard inputs into our processes of practical reasoning, perceptual experiences play the role of standard inputs into our processes of theoretical reasoning" (2013, 264).

The analogy between perception and basic desire helps to defuse the following objection to our proposal: (i) basic desires provide reasons for action only if they are rational; but (ii) some basic desires are irrational; so (iii) not all basic desires provide reasons for action. In response, we reject both premises: there are no rational constraints on basic desire, just as there are no rational constraints on perception. Basic desire, like perception, is neither rational, nor irrational, but arational. It falls outside the domain of rational evaluation.

The rationality constraints that are sometimes thought to constrain basic desire are more plausibly regarded as constraints on practical reasoning. For instance, there's nothing irrational about having basic desires with inconsistent contents, so long as you don't have inconsistent intentions. Similarly, there's nothing irrational about having perceptions with inconsistent contents, so long as you don't have inconsistent beliefs. Perception gives you epistemic reasons for belief, but those reasons can be defeated when they conflict. Likewise, basic desires give you practical reasons for intention and action, but again, those reasons can be defeated when they conflict. Just as theoretical reasoning has the function of resolving conflicts in your basic perceptual evidence, so practical reasoning has the function of resolving conflicts in your basic desires. ${ }^{23}$

Now let's turn to our second question. What must basic desires be like in order to play their normative role in providing reasons for action without standing in need of rational support by reasons? Our answer is that only affective experiences, and dispositions to have affective experiences, can play this normative role. We've already argued that some affective experiences, and dispositions to have affective experiences, can provide reasons for action when they are not based on reasons themselves. But why think nothing else can play this normative role? We'll argue for this premise by a process of elimination.

\footnotetext{
${ }^{23}$ Hubin (1991) argues that although basic desires cannot be intrinsically irrational, they can be instrumentally irrational in virtue of conflicting with other basic desires. On our view, this doesn't make our basic desires irrational, but merely defeats their reason-giving force.
} 
The moral we draw from our discussion of Quinn's radioman is that motivational dispositions cannot provide reasons for action when they have no associated phenomenal character. Moreover, not just any kind of phenomenal character will do the job. Experiences with no affective component cannot provide reasons for action because they have no phenomenal valence: their phenomenal character gives them no valenced orientation towards an intentional content. As a result, their phenomenal character provides no reasons to make their intentional contents true, rather than false, or vice versa.

What about a visual experience in which you see that someone is suffering, but without experiencing any valenced orientation towards this content? In that case, you may have a reason to help them, but only because you have reason to believe that there is value in alleviating suffering. Presumably, you do have some reason to believe this, perhaps on a priori grounds, but it doesn't derive solely from your visual experience that someone is suffering. So, visual experience alone cannot play the normative role of providing reasons for action without standing in need of rational support by reasons. In contrast, if you have an affective experience that is negatively valenced towards the content that someone is suffering, then you thereby have a reason to act that derives solely from the valenced phenomenal character of your experience. Affective experience therefore plays a distinctive normative role that cannot be co-opted by experiences with no phenomenal valence.

Evaluative beliefs represent their contents in a positively or negatively valenced way. Nevertheless, they cannot provide reasons for action unless they are rationally based on reasons themselves. Even our most basic evaluative beliefs must be non-inferentially based on reasons, although there is scope for theoretical disagreement about the source of these reasons. Unlike affective experiences, they cannot provide reasons for action without standing in need of any further rational support by reasons. While valence is necessary for a mental state to provide reasons for action, it is not sufficient unless it is disposed to figure in the phenomenal character of affective experience.

We've argued that motivational dispositions, non-valenced experiences, and evaluative beliefs are unsuited to play the distinctive normative role of affective experience. But what else does this leave? In the absence of other plausible candidates, we provisionally conclude that only affective experiences, and dispositions to have affective experiences, can provide reasons for action without standing in need of any further rational support. 
We're now in a position to argue for the affective theory of basic desire, according to which all basic desires are affective experiences, or dispositions to have affective experiences. Here is the argument in outline:

(1) All basic desires are mental states that provide reasons for action without standing in need of any further rational support by reasons.

(2) Affective experiences, and dispositions to have affective experiences, are the only mental states that can provide reasons for action without standing in need of any further rational support by reasons.

(3) Therefore, all basic desires are affective experiences, or dispositions to have affective experiences.

On this affective theory, to have a basic desire that $p$ is to feel or be disposed to feel either positively about the prospect that $p$ or negatively about the prospect that not- $p$.

We don't claim that all desires are affective experiences or affective dispositions. After all, you don't feel positively about everything you desire. You can desire to drink cod liver oil as a means to relieving joint pain without thereby being disposed to feel positively about drinking cod liver oil. But this non-basic desire is best explained as a complex state that consists in your basic desire to avoid joint pain and your belief that drinking cod liver oil is a way to relieve joint pain. On this view, all basic and non-basic desires are explained directly or indirectly in terms of affective experience.

Michael Smith argues against what he calls the strong phenomenological conception of desire: that is, "the view that desires are, like sensations, simply and essentially states that have a certain phenomenological content" $(1994,105)$. He argues that, unlike sensations, desires don't have their phenomenal character essentially, since they can persist through periods of time in which they have no phenomenal character at all. We're inclined to agree. Desires are dispositional states: they are disposed to cause feelings of desire, but they are distinct from the feelings of desire they are disposed to cause. Moreover, like other dispositions, they can persist through time when they are not currently being manifested. We therefore propose what we call the weak phenomenological conception of desire, according to which basic desires are individuated not by their phenomenal character, but rather by their phenomenal dispositions - that is, by their dispositions to cause the phenomenal character 
of affective experiences of desire. In the next section, we'll defend this proposal against orthodox versions of functionalism that explain desire in terms of its motivational role.

\section{Desire and Motivation}

What is the connection between desire and motivation? Everyone can agree that desires normally play a causal role in motivating action. To use the standard example: if I want to drink beer, and I believe there is beer in the fridge, then other things being equal, I'll be motivated to open the fridge to get beer. The motivational theory of desire, however, makes a much stronger claim. It says that to have a desire is to be motivated to act in ways that one believes will promote the satisfaction of one's desire. So, for example, Robert Stalnaker writes, "To desire that $p$ is to be disposed to act in ways that would tend to bring it about that $p$ in a world in which one's beliefs, whatever they are, were true" $(1984,15)$.

If the motivational theory is true, then the affective theory is false. The motivational theory says that it's necessary and sufficient for having a basic desire to $\varphi$ that one is suitably motivated to $\varphi$. And yet it is neither necessary nor sufficient for being suitably motivated to $\varphi$ that one is disposed to feel positively about $\varphi$-ing. After all, there are possible cases in which affective experiences are dissociated from their normal causal role in motivating action. Therefore, if the motivational theory is true, then the affective theory is false: it is neither necessary nor sufficient for having a basic desire to $\varphi$ that one is disposed to feel positively about $\varphi$-ing. Our goal in this section is to defend the affective theory against this objection by arguing that the motivational theory is false: motivation is neither necessary nor sufficient for basic desire. ${ }^{24}$

The objection can be divided into two parts: an argument that affective experience is not necessary for basic desire, and an argument that it's not sufficient for basic desire. Let's start with the argument against necessity:

(N1) It is sufficient for having a basic desire to $\varphi$ that one is suitably motivated to $\varphi$.

(N2) It is not necessary for being suitably motivated to $\varphi$ that one is disposed to feel positively about $\varphi$-ing.

\footnotetext{
${ }^{24}$ Schroeder (2004, Ch. 1) gives different arguments for the same conclusion.
} 
(N3) Therefore, it is not necessary for having a basic desire to $\varphi$ that one is disposed to feel positively about $\varphi$-ing.

The moral we draw from our discussion of radioman is that motivation is not sufficient for basic desire. Our basic desires don't just motivate us to act, but also provide us with reasons to act, and thereby motivate us to act rationally on the basis of those reasons. Although radioman is motivated to turn on radios, he has no reason to turn on radios, and so he cannot act rationally on the basis of reasons. If we don't build rationality into the motivational role of desire, then (N2) is true, but (N1) is false: motivation is not sufficient for desire unless it is rational motivation. But if we build rationality into the motivational role of desire, then (N1) is true, but (N2) is false: affective dispositions are necessary for the kind of rational motivation that is sufficient for desire. Either way, the argument fails.

We conclude that basic desires must be affective dispositions in order to provide reasons for action and hence to motivate action that is performed rationally on the basis of those reasons. We can also recognize a more general category of motivational states that combine with representational states to produce behavior. This category has an important role to play in explaining motivated but non-rational behavior in both conscious and unconscious creatures. But this concept of a motivational state is much broader than the concept of desire that we are trying to analyze. In our folk theory of mind, desires play a normative role in providing reasons for action and not just a causal role in motivating action.

It may be said that motivational dispositions are necessary for basic desire even if they're not sufficient. Thus, Quinn writes:

I am not saying, however, that desire is in general nothing more than positive evaluation. In some cases we would not speak of desire if the implicit positive evaluation did not provoke or were not accompanied by some kind of appetite that prods the will toward the object for the good that it seems to offer. $(1993,247)$

If motivational dispositions are necessary for basic desire, then affective dispositions are not sufficient. At best, basic desire is a complex, multi-track disposition that includes both affective dispositions and motivational dispositions.

Here is the argument against sufficiency: 
(S1) It is necessary for having a basic desire to $\varphi$ that one is suitably motivated to $\varphi$.

(S2) It is not sufficient for being suitably motivated to $\varphi$ that one is disposed to feel positively about $\varphi$-ing.

(S3) Therefore, it is not sufficient for having a basic desire to $\varphi$ that one is disposed to feel positively about $\varphi$-ing.

The conclusion (S3) is inconsistent with our claim that affective dispositions are sufficient for basic desire. We accept (S2) because it seems possible that affective experiences can be dissociated from their normal causal role in the motivation of action. Recall that Lewis' madman is motivated to prevent pleasure despite feeling attracted to it, and to pursue pain despite feeling averse to it. More generally, we can suppose that his feelings of attraction motivate him to avoid their objects, and his feeling of aversion motivate him to pursue them. In that scenario, we'll argue, his desires go with his feelings of attraction and aversion, rather than his motivational dispositions. We therefore reject (S1). ${ }^{25}$

Our argument against (S1) is that affective experiences, and dispositions to have affective experiences, can provide reasons for action without thereby motivating action. The madman, for example, has reasons to pursue what he feels attracted to, and to avoid what he feels averse from, despite the fact that he is motivated to do the opposite. For example, he has good reasons to do what he can to avoid pain, since it feels awful to him and the prospect of enduring pain fills him with fear and loathing. Of course, he is not motivated to avoid pain, but to pursue it instead, so he fails to act rationally on the basis of the good reasons he has. That is an unfortunate predicament, but it doesn't mean that he has no good reason to avoid pain.

Like the madman, we sometimes have good reasons for acting that we're not motivated to act upon. Indeed, we're not always capable of acting on the good reasons we have - say, to remain calm in the face of adversity or to stop obsessively thinking about

${ }^{25}$ Compare Strawson's $(1994,251)$ example of the Weather Watchers, who have thoughts and feelings, beliefs and desires, but no dispositions to behave in any way. Strawson's discussion is generally congenial to ours, although he endorses a hedonic theory of desire, which is distinct from our affective theory of desire (see section 4.3). 
things that make us upset. If we were fully rational, then of course we would always be motivated to act on the balance of reasons. Sadly, however, we're not fully rational. Perhaps there are principled limits on how much irrationality is compatible with having beliefs and desires at all, but that goes beyond anything we've argued for here. In any case, it's not just a remote possibility, but an undeniable fact about the actual world that we're not always motivated to act rationally on the basis of our reasons. ${ }^{26}$

Desires normally play a causal role in motivating action, but this is a contingent truth if it's a truth at all. In contrast, it's a necessary truth that desires play a normative role in providing reasons for action. This has important consequences for the prospects of giving a functionalist theory of desire: if there is any functional role that is necessary and sufficient for desire, then it is a normative role, rather than a merely causal role. On our account, however, the most fundamental account of the nature of desire is given neither in terms of its causal role in motivating action nor its normative role in providing reasons for action. Instead, we claim that desires play these normative and motivating roles in virtue of their dispositions to cause the phenomenal character of affective experience. On our account of desire, then, affective experience comes first.

\section{Conclusions}

In conclusion, the concept of desire is associated with at least three different roles:

(1) The motivational role: desires motivate action.

(2) The normative role: desires provide reasons for action.

(3) The phenomenological role: desires cause feelings of desire.

In this paper, we've argued that these three roles are importantly connected. First, we've argued that the motivational role of desire should be understood in terms of its normative

\footnotetext{
${ }^{26}$ We thereby reject a strong version of what Darwall (1983) calls existence internalism: the thesis that you have a reason to $\varphi$ only if you're motivated to $\varphi$. But we accept Korsgaard's internalism requirement, which states that, "reasons for action must be capable of motivating rational persons" $(1986,11)$. As she notes, however, this requirement is so weak that "there is probably no moral theory that it excludes" $(1986,23)$.
} 
role: desires don't just motivate action, but also provide reasons for action, and thereby motivate us to act rationally on the basis of reasons. And second, we've argued that the normative role of desire should be understood in terms of its phenomenological role. Desires provide reasons for action, and thereby motivate us to act rationally on the basis of reasons, only because they are disposed to make us feel positively about the things we desire. Under the influence of causal functionalism, now finally beginning to wane, the connections between desire and affective experience have been very much underappreciated. ${ }^{27}$

\footnotetext{
${ }^{27}$ This paper is joint work: the authors are listed in alphabetical order. This paper was first presented at SLACRR in 2011, and more recently at the University of Tennessee, ANU, Melbourne and Sydney in 2016 and 2017. We are grateful to audiences on those occasions, and especially to Justin D’Arms, Don Hubin, Robert Kraut, Eden Lin, Karl Schafer, Sigrún Svavarsdóttir, and Ariela Tubert for invaluable comments and discussion.
} 


\section{References}

Anscombe, G.E.M. 1963. Intention, $2^{\text {nd }}$ edition. Blackwell.

Arpaly, Nomy. 2003. Unprincipled Virtue. Oxford University Press.

Block, Ned. 1995. "On a Confusion about a Function of Consciousness." Behavioral and Brain Sciences 18.2: 227-47.

BonJour, Laurence. 1985. The Structure of Empirical Knowledge. Harvard University Press.

Broome, John. 1999. “Normative Requirements.” Ratio 12.4: 398-419.

Chalmers, David. 2004. “The Representational Character of Experience.” In The Future for Philosophy, edited by B. Leiter. Clarendon Press, 153-182.

Chang, Ruth. 2004. "Can Desires Provide Reasons for Action?" In Reason and Value: Themes from the Moral Philosophy of Joseph Raz, edited by R. J. Wallace, P. Pettit, S. Scheffler, and M. Smith. Oxford University Press, 56-91.

Crane, Tim. 2009. "Intentionalism." In The Oxford Handbook to the Philosophy of Mind, edited by A. Beckermann and B. McLaughlin. Oxford University Press, 474-93.

Dancy, Jonathan. 2000. Practical Reality. Clarendon Press.

Darwall, Stephen. 1983. Impartial Reason. Cornell University Press.

Davidson, Donald. 1963. “Actions, Reasons, and Causes.” The Journal of Philosophy 60.23: 685700.

Döring, Sabine. 2007. "Seeing What to Do: Affective Perception and Rational Motivation." Dialectica 61.3: 363-394.

Gibbard, Alan. 1990. Wise Choices, Apt Feelings. Harvard University Press.

Goldie, Peter. 2000. The Emotions: A Philosophical Exploration. Oxford University Press.

Horgan, Terry and John Tienson. 2002. "The Intentionality of Phenomenology and the Phenomenology of Intentionality." In Philosophy of Mind: Classical and Contemporary Readings, edited by D. Chalmers. Oxford University Press, 520-534.

Hubin, Don. 1991. "Irrational Desires.” Philosophical Studies 62.1: 23-44.

Johnston, Mark. 2001. "The Authority of Affect." Philosophy and Phenomenological Research 63.1: 181-214.

Korsgaard, Christine. 1986. "Skepticism about Practical Reason.” Journal of Philosophy 83.1: 525

Lewis, David. 1980. "Mad Pain and Martian Pain." In Readings in Philosophy of Psychology: Volume I, edited by N. Block. Harvard University Press, 216-32. 
McDowell, John 1985. "Values and Secondary Qualities." In Morality and Objectivity, edited by T. Honderich. Routledge, 110-29.

Montague, Michelle. 2009. "The Logic, Intentionality, and Phenomenology of Emotion." Philosophical Studies 145: 171-192.

Nagel, Thomas. 1970. The Possibility of Altruism. Oxford: Clarendon Press.

Oddie, Graham. 2005. Value, Reality, and Desire. Oxford University Press.

Parfit, Derek. 1984. Reasons and Persons. Oxford University Press.

Quinn, Warren. 1993. "Putting Rationality in its Place." In Morality and Action. Cambridge University Press, 228-255.

Raz, Joseph. 1999. Engaging Reason: On the Theory of V alue and Action. Oxford University Press.

Reisner, Andrew. 2013. "Prima Facie and Pro Tanto Oughts." In The International Encyclopedia of Ethics, edited by H. LaFollette. Blackwell.

Scanlon, T. M. 1998. What We Owe to Each Other, Harvard University Press.

Schafer, Karl. 2013. "Perception and the Rational Force of Desire." Journal of Philosophy 110.5: 258-281.

Schapiro, Tamar. 2009. “The Nature of Inclination.” Ethics 119.2: 229-256.

Schroeder, Mark. 2007. Slaves of the Passions. Oxford University Press.

Schroeder, Mark. 2008. "Having Reasons.” Philosophical Studies 139.1: 57-71.

Schroeder, Timothy. 2004. Three Faces of Desire. Oxford University Press.

Shoemaker, Sydney. 1996. The First Person Perspective and Other Essays. Cambridge University Press.

Smith, Michael. 1994. The Moral Problem, Blackwell Publishing.

Smith, Michael. 2011. "Scanlon on Desire and the Explanation of Action." In Reasons and Recognition: Essays on the Philosophy of T.M. Scanlon, edited by R. J. Wallace, R. Kumar, and S. Freeman. Oxford University Press, 79-97.

Smithies, Declan. 2012. Moore's Paradox and the Accessibility of Justification. Philosophy and Phenomenological Research 85.2: 273-300.

Smithies, Declan. 2014. The Phenomenal Basis of Epistemic Justification. In New Waves in Philosophy of Mind, edited by M. Sprevak and J. Kallestrup. Palgrave Macmillan, 98124.

Smithies, Declan. Forthcoming. The Epistemic Role of Consciousness. Oxford University Press. Sprigge, Timothy. 1988. The Rational Foundations of Ethics. Routledge \& Kegan Paul. 
Stalnaker, Robert. 1984. Inquiry. Bradford Books.

Stampe, Dennis. 1987. “The Authority of Desire.” Philosopbical Review 96: 335-381.

Strawson, Galen. 1994. Mental Reality. MIT Press.

Tappolet, Christine. 2016. Emotions, V alues, and Agency. Oxford University Press.

Tenenbaum, Sergio. 2007. Appearances of the Good: An Essay on the Nature of Practical Reason. Cambridge University Press.

Tye, Michael. 1995. Ten Problems of Consciousness. MIT Press.

Weiss, Jeremy. 2016. A Feeling Theory of Feelings. Ph.D. Thesis, The Ohio State University.

Williams, Bernard. 1981. "Internal and External Reasons." In Moral Luck. Cambridge University Press, 101-114. 